\title{
CULTIVO E PRODUÇÃO DE BIOMASSA DA CIANOBACTÉRIA Spirulina COM MONOETANOLAMINA E RECICLO DE NUTRIENTES
}

\author{
G. M. ROSA ${ }^{1}$, L. MORAES ${ }^{1}$, B. B. CARDIAS ${ }^{1}$, SOUZA, M. R. A. Z., COSTA, J. A. V. \\ ${ }^{1}$ Universidade Federal do Rio Grande, Escola de Química e Alimentos, Laboratório de \\ Engenharia Bioquímica \\ E-mail para contato: jorgealbertovc@terra.com.br
}

\begin{abstract}
RESUMO - O cultivo de microalgas converte $\mathrm{CO}_{2}$ em biomassa por processo biológico, ao passo que a fixação química de $\mathrm{CO}_{2}$ é realizada artificialmente com melhores resultados. Assim, unir estes processos pode ser uma alternativa para aumentar a captura deste gás de efeito estufa com menor impacto ambiental. Neste contexto, o objetivo deste trabalho foi avaliar a influência de monoetanolamina no cultivo de Spirulina sp. LEB 18. Para isso, cultivos foram conduzidos em modo semicontínuo, com reciclo de meio, com adição de MEA e sem adição de MEA, em fotobiorreatores tubulares de $2,0 \mathrm{~L}$, a $30{ }^{\circ} \mathrm{C}$, fotoperíodo de $12 \mathrm{~h}$ claro/ $12 \mathrm{~h}$ escuro, 41,6 $\mu \mathrm{mol}_{\text {fótons }} \cdot \mathrm{m}^{-2} \cdot \mathrm{s}^{-1}$, por $25 \mathrm{~d}$. Nos ensaios com MEA foram obtidos os maiores resultados de produtividade de biomassa $\left(62,1 \mathrm{mg} \cdot \mathrm{L}^{-1} \cdot \mathrm{d}^{-1}\right)$, eficiência de utilização de $\mathrm{CO}_{2}\left(15,8 \% \mathrm{~m} \cdot \mathrm{m}^{-1}\right)$, biomassa gerada $(3,57 \mathrm{~g})$ e concentração de carboidratos na biomassa (96,0 \% superior ao ensaio sem MEA). Assim, Spirulina pode unir a biofixação de $\mathrm{CO}_{2}$ com a produção de biomassa enriquecida com carboidratos.
\end{abstract}

\section{INTRODUÇÃO}

O aumento na demanda por combustíveis fósseis nos últimos anos desperta o interesse crescente em fontes renováveis de energia baseadas na transformação de biomassa (ELLIOTT et al., 2013). Entre estas, a biomassa de microalgas tem potencial para fornecer energia renovável, oriunda do biodiesel, bioetanol, biohidrogênio e biogás. Além disso, estes micro-organismos têm a capacidade de sintetizar moléculas bioativas, tais como carotenoides, ácidos graxos, antioxidantes, anti-inflamatórios e outros compostos orgânicos valiosos, os quais podem ser utilizados na alimentação, em produtos farmacêuticos e cosméticos, bem como compor biomateriais e nanoestruturas (FERREIRA et al., 2013).

O cultivo semicontínuo é um modo de condução em que uma porção do meio de cultivo é removido periodicamente e o restante é utilizado como o ponto de partida para a continuação da cultura. A quantidade relativa de meio novo adicionado é chamada de "taxa de renovação" e a concentração de biomassa no momento da adição deste meio novo é chamada "concentração de corte" (REICHERT et al., 2006). Este modo de cultivo evita a ocorrência de baixa taxa de divisão celular no início do processo, bem como diminui limitações no que se refere a nutrientes e à penetração da luz no interior da cultura (HO et al., 2012). Contudo, a adição de meio de cultivo 


\section{9 a 22 de outubro de 2014 \\ Florianópolis/SC}

novo a cada corte traz como consequência o aumento da pressão osmótica do meio, o que, segundo Sudhir et al. (2005), prejudica o aparato fotossintético de microalgas como Spirulina.

O aumento da pressão osmótica no meio diminui a solubilidade do $\mathrm{CO}_{2}(\mathrm{GREEN} \mathrm{e} \mathrm{PERRY,}$ 2008), a qual é governada pelo equilíbrio termodinâmico da dissociação do ácido carbônico (KIM et al., 2013). Logo, a biofixação de $\mathrm{CO}_{2}$ por microalgas seria melhorada se maior concentração do gás fosse dissolvido no meio líquido. Ao encontro disso, absorventes químicos, como a monoetanolamina (MEA), podem aumentar a mitigação de $\mathrm{CO}_{2}$ para o meio de cultivo. Neste contexto, cultivar microalgas em modo semicontínuo com reciclo de nutrientes e adição de absorvente químico pode ser uma alternativa para reduzir os custos com nutrientes e maximizar a produção de biomassa e a biofixação de $\mathrm{CO}_{2}$.

Diante disso, o objetivo deste trabalho foi avaliar a influência da adição de monoetanolamina na produção de biomassa e na concentração das principais macromoléculas de Spirulina.

\section{MATERIAL E MÉTODOS}

\subsection{Manutenção do inóculo}

O micro-organismo utilizado foi Spirulina sp. LEB 18 (MORAIS et al., 2008). A manutenção do inóculo desta microalga com $\mathrm{CO}_{2(\mathrm{~g})}$ como fonte de carbono foi alcançada pela decantação do mesmo, ressuspensão em meio Zarrouk (ZARROUK, 1966) sem carbono e a alimentação $\left(0,12 \mathrm{~mL} \mathrm{CO}_{2} \cdot \mathrm{mL}_{\text {meio }}{ }^{-1} \cdot \mathrm{d}^{-1}\right)$ com o gás, $1 \mathrm{~min}$, a cada $1 \mathrm{~h}$, durante o período claro.

\subsection{Condições de cultivo}

Os ensaios foram realizados com concentração celular inicial de 0,20 g.L.-1, a $30{ }^{\circ} \mathrm{C}$, fotoperíodo $12 \mathrm{~h}$ claro/12 h escuro, $41,6 \mu \mathrm{mol}_{\text {fótons. }} \mathrm{m}^{-2} \cdot \mathrm{s}^{-1}$, agitação promovida pela injeção de ar comprimido (RADMANN e COSTA, 2008). Os experimentos foram realizados em duplicata, com adição de monoetanolamina (MEA, $\mathrm{C}_{2} \mathrm{H}_{7} \mathrm{NO}$ ), sem adição de MEA (ensaio controle), em fotobiorreatores tubulares verticais (FBRT) de 2,0 L (com 1,8 L de volume útil), por $25 \mathrm{~d}$, conduzidos de forma semicontínua. $\mathrm{O}_{\mathrm{CO}_{2}}$ foi adicionado em vazão específica de 0,36 $\mathrm{mL} \mathrm{CO}_{2} \cdot \mathrm{mL}_{\text {meio }}{ }^{-1} \cdot \mathrm{d}^{-1}, 2 \mathrm{~min}$, a cada $1 \mathrm{~h}$, durante o período claro. A concentração celular de corte foi $0,5 \mathrm{~g} \mathrm{~L}^{-1}$ (REICHERT et al., 2006) e a fração volumétrica de reciclo de meio foi 0,5 , sendo que a cada reciclo de meio foi adicionado $0,20 \mathrm{mmol} . \mathrm{L}^{-1}$ de MEA.

\subsection{Determinações analíticas}

Os ensaios tiveram monitorados diariamente a concentração de biomassa, $\mathrm{pH}$ e alcalinidade. Nos dias em que a concentração de biomassa atingiu a concentração de corte foram retiradas amostras também após a realização do corte. A concentração de biomassa foi determinada por densidade óptica das culturas a $670 \mathrm{~nm}$ em espectrofotômetro (QUIMIS Q798DRM, Diadema SP - Brasil), a partir de curva de calibração que relacionou a densidade óptica e massa seca da microalga. $\mathrm{O}$ pH foi determinado por medição direta da amostra com pHmetro digital (PH-221, 
LUTRON - Taiwan) e a alcalinidade por titulação potenciométrica (APHA, 1998). A concentração de carbono inorgânico dissolvido (CID) foi calculada a partir das frações de ionização do carbono no meio de acordo com Carmouze (CARMOUZE, 1994).

\subsection{Respostas avaliadas do cultivo}

A produtividade de biomassa $\left(\mathrm{P}_{\mathrm{x}}, \mathrm{mg} \cdot \mathrm{L}^{-1} \cdot \mathrm{d}^{-1}\right)$ (Equação 1) foi obtida com a concentração de biomassa $\left(\mathrm{X}, \mathrm{mg} . \mathrm{L}^{-1}\right)$ no tempo $\mathrm{t}(\mathrm{d})$ e a concentração de biomassa $\left(\mathrm{X}_{0}, \mathrm{mg} \cdot \mathrm{L}^{-1}\right)$ no tempo to $(\mathrm{d})$. A velocidade específica máxima de crescimento $\left(\mu_{\text {máx }}, \mathrm{d}^{-1}\right)$ foi calculada por regressão linear aplicada à fase logarítmica de crescimento de cada ciclo em um perfil $\ln X\left(\mathrm{~g} . \mathrm{L}^{-1}\right)$ contra $\mathrm{t}(\mathrm{d})$, no qual o coeficiente angular da reta obtida é $\mu_{\text {máx }}$. A partir deste perfil também foi obtido o tempo de geração ( $\mathrm{t}_{\mathrm{g}}$ ) (Equação 2). A eficiência de utilização de $\mathrm{CO}_{2}\left(\mathrm{E}, \% \mathrm{~m} \cdot \mathrm{m}^{-1}\right)$ foi calculada segundo a Equação 3 , a partir da produtividade de biomassa $\left(\mathrm{P}_{\mathrm{x}}, \mathrm{mg} \cdot \mathrm{L}^{-1} \cdot \mathrm{d}^{-1}\right)$, fração mássica de carbono na biomassa $\left(\mathrm{x}_{\mathrm{cbm}}\right)$, massas molares de dióxido de carbono $\left(\mathrm{M}_{\mathrm{CO} 2}\right)$ e carbono $\left(\mathrm{M}_{\mathrm{C}}\right)$, volume útil do fotobiorreator $\left(\mathrm{V}_{\text {útil }}, \mathrm{L}\right)$ e a taxa mássica de alimentação com $\mathrm{CO}_{2}\left(\dot{\mathrm{m}}, \mathrm{mg} \cdot \mathrm{d}^{-1}\right)$. A biomassa gerada ao final dos ensaios $\left(\mathrm{B}_{\mathrm{g}}, \mathrm{g}\right)$ (Equação 5) foi calculada com a concentração de biomassa obtida ao final de cada ciclo de crescimento $\left(\mathrm{X}_{\mathrm{fi}}, \mathrm{g} \cdot \mathrm{L}^{-1}\right)$, a concentração de biomassa no início de cada ciclo de crescimento $\left(\mathrm{X}_{\mathrm{ii}}, \mathrm{g} . \mathrm{L}^{-1}\right)$ e o volume de cultivo retirado em cada corte $\left(\mathrm{V}_{\mathrm{Ci}}, \mathrm{L}\right)$.

$$
\begin{aligned}
& P_{x}=\left(\frac{X-X_{0}}{t-t_{0}}\right) \\
& t_{g}=\frac{\ln 2}{\mu_{\text {máx }}} \\
& E=P_{x} * x_{c b m} * \frac{M_{C O}}{M_{C}} * V_{u ́ t i l} * \frac{1}{\dot{m}} * 100 \\
& B_{g}=\sum\left[\left(X_{f 1}-X_{i 1}\right) V_{C 1}+\left(X_{f 2}-X_{i 2}\right) V_{C 2}+\ldots+\left(X_{f n}-X_{i n}\right) V_{C n}\right]
\end{aligned}
$$

\subsection{Recuperação da biomassa}

A biomassa obtida a cada corte foi separada por centrifugação (HITACHI himac CR-GIII, Tóquio - Japão) a $15200 \mathrm{~g}, 15$ min e $20{ }^{\circ} \mathrm{C}$, ressuspendida em água destilada e novamente centrifugada nas mesmas condições. Posteriormente, a biomassa foi concentrada a $50 \mathrm{~mL}$ em recipiente estéril, congelada a $-80{ }^{\circ} \mathrm{C}$, liofilizada e armazenada a $-20{ }^{\circ} \mathrm{C}$ até sua caracterização.

\subsection{Caracterização da biomassa}

Macromoléculas: a análise de proteínas e carboidratos foi realizada a partir de extratos preparados $(5 \mathrm{mg}$ de biomassa microalgal e $10 \mathrm{~mL}$ de água destilada) sonicados em sonda ultrassônica, com ciclos de 20 min (1 min ligado e 1 min desligado); a concentração de proteínas foi determinada a partir de método colorimétrico (LOWRY et al., 1951) e a concentração de 
carboidratos foi determinada por método colorimétrico fenol-sulfúrico (DUBOIS et al., 1956); a concentração de lipídios foi determinada pelo método de Folch (FOLCH et al., 1957).

Análise elementar de carbono e nitrogênio: foi realizada a cada corte e ao final dos ensaios em Analisador Elementar CHNS/O Serie 2400 (Perkin Elmer).

\subsection{Análise estatística}

As respostas obtidas foram avaliadas através de análise de variância, seguida por teste de Tukey, com nível de $95 \%$ de confiança.

\section{RESULTADOS E DISCUSSÃO}

O experimento com MEA alcançou 8 ciclos de crescimento (Figura 1a) em fase log com coeficiente de determinação $\left(\mathrm{R}^{2}\right)$ de 0,9826, 0,9963, 0,9933, 0,9832, 0,9853, 0,9998, 0,9888, 0,9999. Este fato aponta que a adição do MEA a cada corte, combinado ao reciclo de nutrientes, foi benéfico ao crescimento de Spirulina. O ensaio controle apresentou 5 ciclos de crescimento, sendo obtida fase lag nos 3 primeiros dias, fase log nos 4 primeiros ciclos e em 4 dias do $5^{\circ}$ ciclo. Além disso, sem a adição do MEA a microalga atingiu a fase estacionária a partir do $20^{\circ} \mathrm{d}$ de ensaio (Figura 1b).

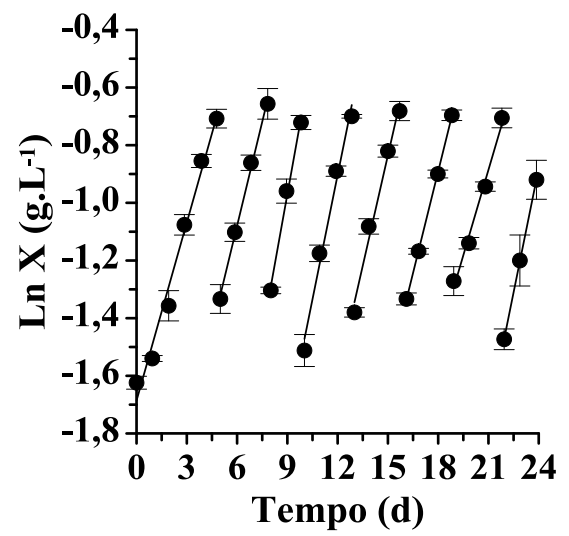

(a)

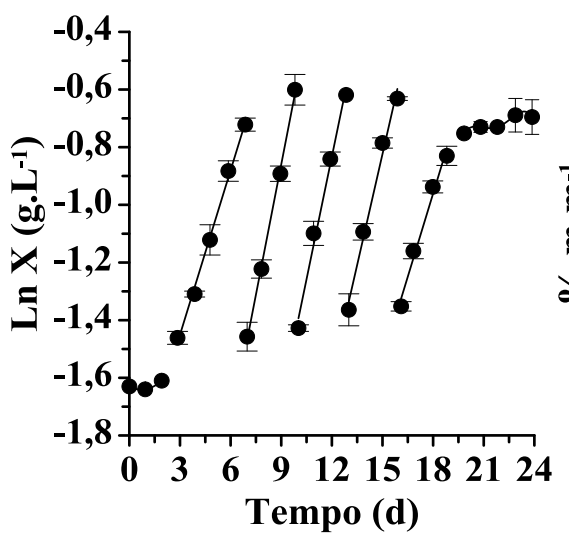

(b)

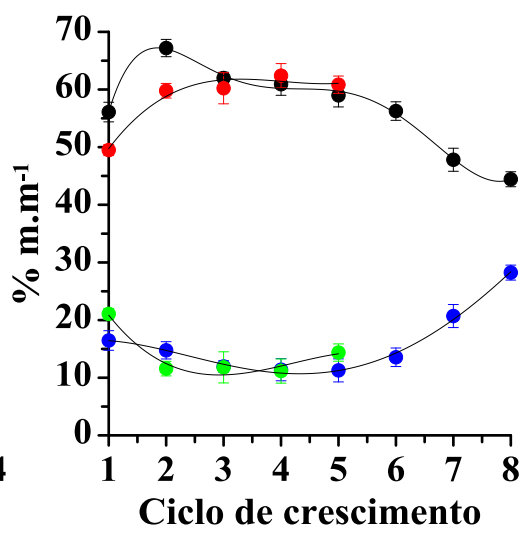

(c)

Figura 1 - Perfis médios linearizados de concentração celular de Spirulina sp. LEB 18 obtidos com MEA (a) e no ensaio controle (b); concentração média de proteínas (com MEA $(\bullet)$ e ensaio controle $(\bullet))$ e carboidratos (com MEA $(\bullet)$ e ensaio controle $(\bullet))(c)$.

O retardo do crescimento pode ocorrer devido ao período de adaptação fisiológica provocado por mudanças nas concentrações de nutrientes (LEE e SHEN, 2004), como por exemplo, o reciclo de meio. A existência de fase log em todos os ciclos de crescimento no ensaio com MEA mostrou que a adição de $0,2 \mathrm{mmol} . \mathrm{L}^{-1}$ do absorvente químico a cada corte, combinado com o reciclo de nutrientes, foi benéfico à multiplicação celular de Spirulina sp. LEB 18. Contudo, em ambas as condições testadas neste trabalho, com ou sem adição de absorvente químico, houve deposição de matéria orgânica na superfície lateral interna dos biorreatores. Este fato pode ter inibido a 

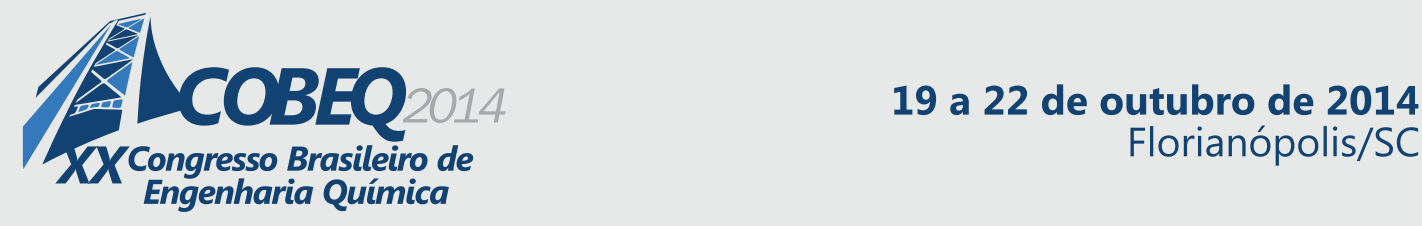

Florianópolis/SC

disponibilidade de luz para o crescimento da microalga, em ambas as condições proporcionadas, devido à blindagem (CHEN et al. 2013) deste material orgânico presente.

A solubilidade do dióxido de carbono no meio líquido diminui com o aumento da temperatura e da concentração salina (GREEN e PERRY, 2008). O meio Zarrouk é composto por uma concentração elevada de sais inorgânicos quando comparado a outros meios de cultivo. Desta forma, a pressão osmótica no meio Zarrouk pode limitar a dissolução de gases mesmo na presença de absorvente químico de $\mathrm{CO}_{2}$. $\mathrm{O}$ pH do ensaio com adição de MEA e do ensaio controle apresentaram comportamento semelhante ao longo do cultivo de Spirulina. Este parâmetro variou entre as médias 7,1 e 8,9 para o ensaio com MEA e entre 6,9 e 8,8 para o ensaio controle. $\mathrm{O} \mathrm{CO}_{2}$ dissolvido no meio participa do equilíbrio químico $\mathrm{CO}_{2(\mathrm{~g})} \leftrightarrow \mathrm{CO}_{2(\mathrm{aq})} \leftrightarrow \mathrm{H}_{2} \mathrm{CO}_{3} \leftrightarrow \mathrm{HCO}_{3}{ }^{-} \leftrightarrow \mathrm{CO}_{3}{ }^{2-}$ . Sendo assim, estes intervalos de pH obtidos podem ser um indicativo de que o carbono estava presente na forma de bicarbonato (RICHMOND, 2004), que é uma das formas preferenciais da microalga absorver carbono (KIM et al., 2013). Neste contexto, as condições empregadas no cultivo de Spirulina no presente estudo não mostraram diferença evidente entre o cultivo com adição de MEA e o cultivo controle no que diz respeito à concentração de carbono inorgânico dissolvido (CID), já que a variação entre valores iniciais e finais foram muito semelhantes $\left(62,4 \pm 0,01 \mathrm{mg} . \mathrm{L}^{-1}-178,4 \pm 4,9 \mathrm{mg} . \mathrm{L}^{-1}\right.$ e $62,0 \pm 0,0 \mathrm{mg} . \mathrm{L}^{-1}-185,2 \pm 0,8 \mathrm{mg} . \mathrm{L}^{-1}$, respectivamente).

Os valores médios dos parâmetros de crescimento $\left(\mu\right.$ máx, $\left.\mathrm{t}_{\mathrm{g}}\right)$, de biofixaçãa de $\mathrm{CO}_{2}(\mathrm{E})$ e as concentrações elementares (carbono e nitrogênio), nos cultivos com e sem adição de MEA, não diferiram estatisticamente ( $\mathrm{p}>0,05)$. Contudo, a adição de MEA proporcionou melhores resultados máximos de todos os parâmetros avaliados (Tabela 1).

Tabela 1 - Resultados obtidos com cultivo de Spirulina com adição de MEA e no cultivo controle de velocidade específica máxima de crescimento $\left(\mu_{\text {máx }}\right)$, tempo de geração $\left(t_{g}\right)$, produtividade de biomassa $\left(\mathrm{P}_{\mathrm{x}}\right)$, eficiência de utilização de $\mathrm{CO}_{2}(\mathrm{E})$, biomassa gerada $\left(\mathrm{B}_{\mathrm{g}}\right)$ concentração elementar de carbono $(\mathrm{C})$ e nitrogênio $(\mathrm{N})$ na biomassa da microalga

\begin{tabular}{|c|c|c|c|c|c|c|c|c|}
\hline & & $\begin{array}{l}\mu_{\text {máx }} \\
\left(d^{-1}\right)\end{array}$ & $\begin{array}{l}\mathbf{t}_{\mathrm{g}} \\
(\mathbf{d})\end{array}$ & $\begin{array}{c}\mathbf{P}_{x} \\
\left(\mathrm{mg}^{-L^{-1}} \cdot \mathbf{d}^{-1}\right)\end{array}$ & $\begin{array}{c}\mathbf{E} \\
\left(\% \mathbf{m} \cdot \mathbf{m}^{-1}\right)\end{array}$ & $\begin{array}{l}\mathbf{B}_{\mathrm{g}} \\
(\mathrm{g})\end{array}$ & $\begin{array}{c}\mathrm{C} \\
\left(\% \mathrm{~m} \cdot \mathrm{m}^{-1}\right)\end{array}$ & $\begin{array}{c}\mathrm{N} \\
\left(\% \mathbf{m} \cdot \mathbf{m}^{-1}\right)\end{array}$ \\
\hline \multirow{5}{*}{$\sum$} & Máximo & 0,323 & 3,51 & 62,1 & 15,8 & 3,57 & 47,2 & 11,2 \\
\hline & Mínimo & 0,198 & 2,15 & 5,6 & 1,4 & 3,17 & 44,9 & 9,0 \\
\hline & Média & $0,254^{\mathrm{a}}$ & $2,80^{\mathrm{a}}$ & $26,3^{\mathrm{a}}$ & $6,7^{\mathrm{a}}$ & $3,35^{\mathrm{a}}$ & $45,8^{a}$ & $10,6^{\mathrm{a}}$ \\
\hline & d. p.* & 0,043 & 0,48 & 0,9 & 0,2 & 0,08 & 0,6 & 0,7 \\
\hline & & $\begin{array}{l}\mu_{\text {máx }} \\
\left(d^{-1}\right)\end{array}$ & $\begin{array}{l}\mathbf{t}_{\mathrm{g}} \\
(\mathrm{d})\end{array}$ & $\begin{array}{c}\mathbf{P}_{\mathbf{x}} \\
\left(\mathbf{m g} \cdot \mathbf{L}^{-1} \cdot \mathbf{d}^{-1}\right)\end{array}$ & $\begin{array}{c}E \\
\left(\% \mathrm{~m}^{-1}\right)\end{array}$ & $\begin{array}{l}\mathbf{B}_{\mathbf{g}} \\
(\mathrm{g})\end{array}$ & $\begin{array}{c}\mathrm{C} \\
\left(\% \mathrm{~m} \cdot \mathrm{m}^{-1}\right)\end{array}$ & $\begin{array}{c}\mathrm{N} \\
\left(\% \mathbf{m} \cdot \mathrm{m}^{-1}\right)\end{array}$ \\
\hline \multirow{4}{*}{ 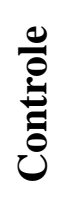 } & Máximo & 0,301 & 3,64 & 44,0 & 11,1 & 2,66 & 46,0 & 11,1 \\
\hline & Mínimo & 0,190 & 2,30 & 14,8 & 3,7 & 2,42 & 45,6 & 9,6 \\
\hline & Média & $0,245^{\mathrm{a}}$ & $2,94^{\mathrm{a}}$ & $29,1^{b}$ & $7,4^{\mathrm{a}}$ & $2,55^{b}$ & $45,8^{\mathrm{a}}$ & $10,5^{\mathrm{a}}$ \\
\hline & d. p. $*$ & 0,051 & 0,64 & 1,0 & 0,3 & 0,11 & 0,2 & 0,7 \\
\hline
\end{tabular}

Letras minúsculas sobrescritas iguais na mesma coluna, para as mesmas respostas, indicam que as médias não diferiram estatisticamente ao nível de $95 \%$ de confiança (p>0,05); *d.p.: desvio padrão amostral. 
A produtividade de biomassa e a biomassa gerada de Spirulina apresentaram comportamento decrescentes ao decorrer dos ciclos de crescimento, semelhante nas duas condições testadas, sendo que os valores médios entre os ciclos de crescimento para $P_{x}$ foram iguais $(p>0,05)$ e a $B g$ foi maior 31,4 \% no ensaio com MEA (p<0,05) (Tabela 1). O máximo $\mu$ máx foi 7,3 \% maior e o mínimo $t_{\mathrm{g}}$ foi $13,5 \%$ menor nos ensaios com MEA em relação ao ensaio controle. Reichert et al. (2006) em cultivo semicontínuo com Spirulina sp. cepa Paracas, com renovação de meio a cada corte, obtiveram $\mu_{\text {máx }}\left(0,101 \mathrm{~d}^{-1}\right)$ e $\mathrm{P}_{\text {máx }}\left(37,0 \mathrm{mg} \cdot \mathrm{L}^{-1} . \mathrm{d}^{-1}\right)$ inferiores aos máximos obtidos no corrente trabalho. Isso ressalta que o uso de meio novo não promove maiores taxas de crescimento e de produtividade de biomassa. Em alguns casos, o reciclo de meio pode provocar uma pequena depleção de nutrientes como o fósforo que, segundo Hu (2004), pode provocar incremento na concentração de compostos de reserva em microalgas procarióticas como Spirulina.

A concentração de proteínas na biomassa de Spirulina produzida com MEA diminuiu a partir do $3^{\circ}$ ciclo de crescimento (Figura 1c) e atingiu o teor médio final de $44,4 \pm 6,9 \% \mathrm{~m} . \mathrm{m}^{-1}$. Este valor está abaixo do que normalmente é encontrado $\left(60-70 \% \mathrm{~m}^{-1} \mathrm{~m}^{-1}\right)$ com esta cepa (BORGES et al., 2013). O perfil da concentração de carboidratos ao longo dos ciclos de crescimento (Figura 1c) nos ensaios com MEA indicam que o reciclo de nutrientes pode ter privado a absorção de nitrogênio por Spirulina e influenciado a rota metabólica da microalga à formação de carboidratos. Este fato pode ser ratificado pela concentração final de carboidratos, na biomassa cultivada com MEA ( $8^{\circ}$ ciclo), ter sido superior àquela cultivada sem MEA $\left(5^{\circ}\right.$ ciclo) (Figura $\left.1 \mathrm{c}\right)$. A concentração de lipídios na biomassa do corrente trabalho, cultivada com MEA $\left(8,3 \pm 1,4 \% \mathrm{~m} \cdot \mathrm{m}^{-1}\right)$ e sem MEA $\left(10,0 \pm 1,2 \% \mathrm{~m} \cdot \mathrm{m}^{-1}\right)$, foi superior ao encontrado por Borges et al. $(2013)\left(5,0 \% \mathrm{~m} \cdot \mathrm{m}^{-1}\right)$ e Morais et al. (2009) (3,3\% m.m $\left.\mathrm{m}^{-1}\right)$ com esta cepa de microalga. Estes autores cultivaram Spirulina em reatores abertos, o que implica, segundo Chisti (2007), em menor produtividade de biomassa, mas não justifica os baixos teores de lipídios em relação aos encontrados nos presentes experimentos.

A depleção de nitrogênio no cultivo de microalgas causa desperdício de luz pela célula por dissipação de energia na forma de calor e luz na forma de fluorescência. Sendo assim, a microalga perderia eficiência no processo fotossintético, podendo diminuir sua produtividade de biomassa e compostos nitrogenados (KLOK et al., 2013). Desta forma, assim como ocorreu com a concentração de carboidratos, a concentração de lipídios pode ter aumentado, nas duas condições testadas, por escassez ou perda de algum nutriente devido ao reciclo de meio. Nestas condições são obtidas baixas concentrações de clorofila $a$ e aumento do conteúdo de carboidratos (HU, 2004). Complementando esta ideia, entende-se que a redução de clorofila está ligada a parte da redução de proteínas, pois segundo Masojídek et al. (2004) estes pigmentos verdes são compostos lipofílicos associados em complexos proteicos de microalgas.

\section{CONCLUSÃO}

A adição de monoetanolamina e o reciclo de meio de cultivo proporcionaram o menor tempo de geração $(2,15 \mathrm{~d})$, maiores resultados de produtividade de biomassa $\left(62,1 \mathrm{mg} \cdot \mathrm{L}^{-1} \cdot \mathrm{d}^{-1}\right)$, biomassa gerada $(3,57 \mathrm{~g})$ e eficiência de utilização de $\mathrm{CO}_{2}\left(15,8 \% \mathrm{~m} \cdot \mathrm{m}^{-1}\right)$. Ao final da batelada semicontínua, a concentração de proteínas na biomassa de Spirulina cultivada com MEA $(44,4 \pm$ $\left.6,9 \% \mathrm{~m} \cdot \mathrm{m}^{-1}\right)$ foi cerca de $37,0 \%$ inferior à do ensaio controle $\left(60,8 \pm 4,0 \% \mathrm{~m} \cdot \mathrm{m}^{-1}\right)$, mas a 
concentração de carboidratos obtidos foi cerca de 96,0 \% superior no ensaio com absorvente químico. Diante do exposto, ficou evidenciado que o cultivo com MEA e reciclo de meio pode ser uma alternativa para aumentar a produção de biomassa e carboidratos de Spirulina sp. LEB 18. Neste contexto, Spirulina pode ser obtida com menores custos com nutrientes, atingindo um espaço em bioprocessos que requeira maiores concentrações desta macromolécula como, por exemplo, a produção de bioetanol.

\section{REFERÊNCIAS}

AMERICAN PUBLIC HEALTH ASSOCIATION (APHA) - Standard Methods. For The Examination of Water and Wastewater. $20^{\circ} \mathrm{ed}$. Washington: American Public Health Association, 1998.

BORGES, J. A.; ROSA, G. M.; MEZA, L. H. R.; HENRARD, A. A.; SOUZA, M. R. A. Z.; COSTA, J. A. V. Spirulina sp. LEB-18 culture using effluent from the anaerobic digestion. Braz. J. Chem. Eng., v. 30, No. 2, p. 277-287, 2013.

CARMOUZE, J. P. O metabolismo dos ecossistemas aquáticos: fundamentos teóricos, métodos de estudo e análises químicas. São Paulo: Editora Edgard Blucher: FAPESP, 253p., 1994.

CHEN, C-Y.; KAO, P-C.; TSAI, C-J.; LEE, D-J.; CHANG, J.-S. Engineering strategies for simultaneous enhancement of C-phycocyanin production and $\mathrm{CO}_{2}$ fixation with Spirulina platensis. Bioresource Technol., v. 145, p. 307-312, 2013.

CHISTI Y. Biodiesel from microalgae. Biotechnol. Adv., v. 25, p. 294-306, 2007.

DUBOIS, M.; GILLES, K. A.; HAMILTON, J. K.; REBERS, P. A.; SMITH, F. Colorimetric method for determination of sugars and related substances. Anal. Chem., v. 28, n. 3, p. 350356, 1956.

ELLIOTT, D. C.; HART, T. R.; SCHMIDT, A. J.; NEUENSCHWANDER, G. G.; ROTNESS, L. J.; OLARTE, M. V.; ZACHER, A. H.; ALBRECHT, K. O.; HALLEN, R. T.;

HOLLADAY, J. E. Process development for hydrothermal liquefaction of algae feedstocks in a continuous-flow reactor. Algal Res., v. 2, p. 445-454, 2013.

FERREIRA, A. F.; RIBEIRO, L. A.; BATISTA, A. P.; MARQUES, P. A. S. S.; NOBRE, B. P.; PALAVRA, A. M. F.; SILVA, P. P.; GOUVEIA, L.; SILVA, C. A. Biorefinery from Nannochloropsis sp. microalga - Energy and $\mathrm{CO}_{2}$ emission and economic analyses. Bioresource Technol., v. 138, p. 235-244, 2013.

FOLCH J.; LEES, M.; STANLEY, G. H. S. A simple method for isolation and purification of total lipids from animal tissues. J. Biol. Chem., v. 226, p. 497-509, 1957.

GREEN, D. W.; PERRY, R. H. Perry's Chemical Engineers' Handbook, USA: McGraw-Hill, 3735 p., 2008.

HO, S-H.; LU, W-B.; CHANG, J-S. Photobioreactor strategies for improving the $\mathrm{CO}_{2}$ fixation efficiency of indigenous Scenedesmus obliquus CNW-N: Statistical optimization of $\mathrm{CO}_{2}$ feeding, illumination, and operation mode. Bioresource Technol., v. 105, p. 106-113, 2012. 
HU, Q. Environmental Effects on Cell Composition. In: RICHMOND, A. Handbook of Microalgal Culture: Biotechnology and Applied Phycology, Blackwell Science, 566 p., 2004. Cap. 5, p. 83-93.

KIM, G.; CHOI, W.; LEE, C-H.; LEE, K. Enhancement of dissolved inorganic carbon and carbon fixation by green alga Scenedesmus sp. in the presence of alkanolamine $\mathrm{CO}_{2}$ absorbents. Biochem. Eng. J., v. 78, p. 18- 23, 2013.

KLOK, A. J.; MARTENS, D. E.; WIJFFELS, R. H.; LAMERS, P. P. Simultaneous growth and neutral lipid accumulation in microalgae. Bioresource Technol., v. 134, p. 233-243, 2013.

LEE, Y-K.; SHEN, H. Basic Culturing Techniques. In: RICHMOND, A. Handbook of Microalgal Culture: Biotechnology and Applied Phycology, Blackwell Science, 566 p., 2004. Cap. 3, p. 40-56.

LOWRY, O. H.; ROSEBROUGH, N. J.; FARR, A. L.; RANDALL, R. J. Protein measurement with the Folin-Phenol reagent. J. Biol. Chem., v. 193, p. 265-276, 1951.

MASOJÍDEK, J.; KOBLÍZEK, M.; TORZILLO, G. Photosynthesis in Microalgae. In: RICHMOND, A. Handbook of Microalgal Culture: Biotechnology and Applied Phycology, Blackwell Science, 566 p., 2004. Cap. 2, p. 20-39.

MORAIS, M. G.; RADMANN, E. M.; ANDRADE, M. R.; TEIXEIRA, G. G.; BRUSCH, L. R. F.; COSTA, J. A. V. Pilot scale semicontinuous production of Spirulina biomass in southern Brazil. Aquaculture, v. 294, p. 60-64, 2009.

MORAIS, M. G.; REICHERT, C. C.; DALCANTON, F.; DURANTE, A. J.; MARINS, L. F.; COSTA, J. A. V. Isolation and Characterization of a New Arthrospira Strain. Z. Naturforsch., v.63, p. 144-150, 2008.

RICHMOND, A. Handbook of Microalgal Culture: Biotechnology and Applied Phycology, London: Blackwell Science, 566 p., 2004.

RADMANN, E. M; COSTA, J. A. V. Conteúdo lipídico e composição de ácidos graxos de microalgas expostas aos gases $\mathrm{CO}_{2}, \mathrm{SO}_{2}$ e NO. Quím. Nova, v. 31, nº 7, p. 1609-1612, 2008.

REICHERT, C. C.; REINEHR, C. O.; COSTA, J. A. V. Semicontinuous cultivation of the cyanobacterium Spirulina platensis in a closed photobioreactor. Braz. J. Chem. Eng., v. 23, No. 01, p. 23-28, 2006.

SUDHIR, P-R.; POGORYELOV, D.; KOVÁCS, L.; GARAB, G.; MURTHY, S. D. S. The Effects of Salt Stress on Photosynthetic Electron Transport and Thylakoid Membrane Proteins in the Cyanobacterium Spirulina platensis. J. Biochem. Mol. Biol., v. 38, No. 4, p. 481-485, 2005.

ZARROUK, C. Contribution à l'étude d'unecyanophycée. Influence de diversfacteurs physiques et chimiquessur la croissance et photosynthese de Spirulina maxima Geitler. Ph.D. Thesis, University of Paris, 1966. 